\title{
AN EXAMPLE OF EASY SYNTHESIS OF ACTIVE FILTER AND OSCILLATOR USING SIGNAL FLOW GRAPH MODIFICATION AND CONTROLLABLE CURRENT CONVEYORS
}

\author{
Roman ŠOTNER - Zdeněk HRUBOŠ - Břetislav ŠEVČÍK \\ Josef SLEZÁK - Jiří PETRŽELA — Tomáš DOSTÁL
}

\begin{abstract}
The paper deals with synthesis of active frequency filters and oscillators for applications in the video band. The synthesis is based on the modified signal flow graph design approach in the current mode. The commercially available high frequency current conveyors and second order structures are used. Basic structure is employing loss-less and lossy current mode integrators in two distributed feedback loops. Some of the used active elements allow to control current gain which is very useful in applications. High frequency multi-functional filter and electronically adjustable quadrature oscillator configurations are discussed. Most of the used passive elements (mainly capacitors) are grounded which is suitable for IC implementation. Simulation and experimental results demonstrate function and features very well.
\end{abstract}

Ke y w ords: frequency filters, oscillators

\section{INTRODUCTION}

There are two ways of the design of analog filter circuits. The first one deals with classical approaches based on the voltage opamps in voltage mode where implementation of electronic adjusting is in some cases quite complicated. The usability of the proposed applications is restricted in frequency responses by indispensable influences of the real active elements. The second approach is using of current mode or mixed mode design of circuits where nonstandard active elements are employed. Some of these elements allow to use electronic controlling of its parameters. This approach uses active elements like transconductors, current conveyors, current feedback amplifiers, etc [1], or their modifications like multi-output transconductors [2-4], multi-output current conveyors [5-6], electronically controllable current conveyors (ECCII) [7-8], voltage gain controlled current conveyors (VGC-CCII) [9], etc. Quite interesting approach is to design a novel active element based on the combination of some of the older widely used active elements. In recent years there were theoretically developed many suitable active elements [1] for electronically adjustable circuits. Some examples of these active elements were fabricated on chip. An example is current differencing transconductance amplifier (CDTA) $[1,10-11]$, current conveyor transconductance amplifier (CCTA) [12,13], and their modifications. One typical modification is available in [14]. Similarly there is also useful differential-input buffered transconductance amplifier (DBTA) [15], current follower transconductance amplifier (CFTA) [16] and some types of current followers, inverters and current amplifiers [17-19]. However, many of them are not commercially available for practical applications. Interesting way preferred by many researchers [15] is using of the commercially available elements for building of complicated novel adjustable elements. This approach tries to solve the problem of very high cost of implementation of novel active block on chip. This method is also much faster than chip development. Similar approach was used also in this paper. For the synthesis and design there was used signal flow graph (SFG) approach and simply distributed feedback structure, where small modification of the structure allows to work in the two different applications (multifunctional filter and oscillator). Signal flow graph is constructed for current mode components however output responses are obtained in voltage form. Proposed circuit can work as multifunctional filter or (and this is the main motivation for this work) as fully adjustable quadrature oscillator.

There have been published many multifunctional [2028] or universal [29-33] voltage or current-mode filter realizations. Especially in [29] the recent progress in CM biquads based on the current conveyors is described very well. There are summarized several realizations of the CM biquads, however many of them are very complicated (many active and passive elements, floating capacitors). The circuit mentioned in this paper is quite easy with clear design process from signal flow graph. Multifunctional filter based on the single CCII- and 6 passive elements is described in [20]. Complicated solution which is based on CCII- and CCII+ and 5 passive elements is presented in [21]. Ref. [22] deals with quite complicated multifunctional filter employing two CCII+, one CCIIand 6 grounded passive elements. In $[23,32]$ multifunctional filters with notch response with CCII+, CCII- and

* Department of Radio electronics, Faculty of Electrical Engineering and Communication, Brno University of Technology, Purkyňova 118, PA-556 61200 Brno Czech Republic, xsotne00@stud.feec.vutbr.cz 


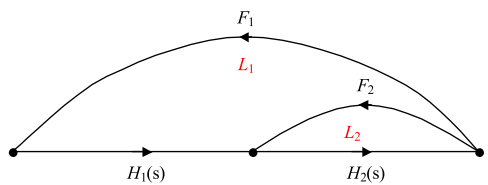

Fig. 1. Signal flow graph of distributed second order feedback system

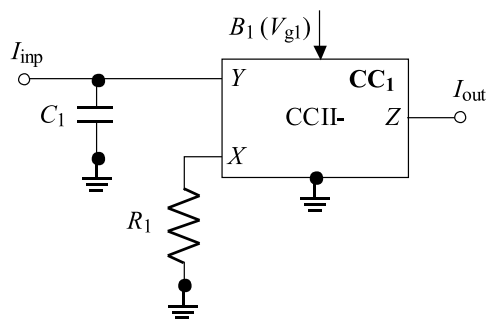

Fig. 2. Loss-less current-mode integrator

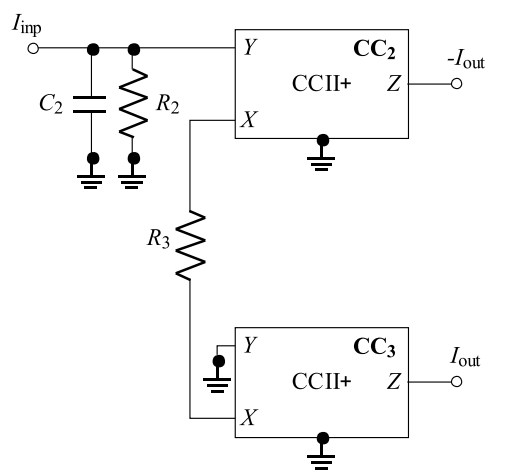

Fig. 3. Current-mode lossy integrator with current distribution and inversion

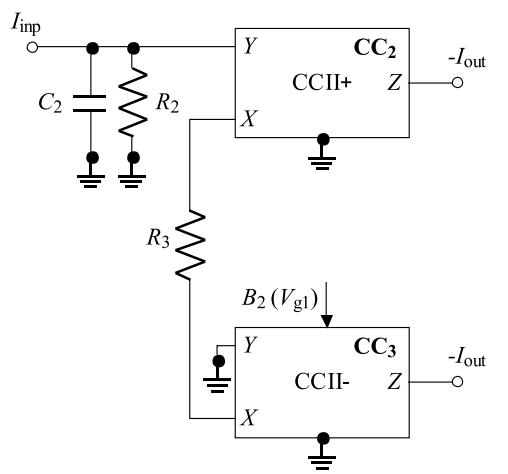

Fig. 4. Current-mode lossy integrator with distribution and adjustable transfer in one output

5-6 passive elements were also introduced. Solution described in [24] shows all-pass, notch and band-pass filter using single CCII+ and 7-9 passive elements. Similarly, one and two current-conveyor-based filter structures providing notch/all-pass responses were reported in $[25,26]$. Other universal structures with CCII \pm and CCCII \pm using minimum passive components are described in [2730]. Publication [31] presents multifunctional filter based on single CCII- and 5 passive elements where notch response is also available. In $[32,33]$ there are other realizations of universal filters based on two or more current con- veyors. We can find many solutions with one, two, three or more active elements and different features. Many of the presented solutions were verified for frequencies of several $\mathrm{kHz}$. The multifunctional active filter is the first application of SFG (Fig. 1) which we discuss in this paper. Presented circuit was proposed for high frequency applications in the range of several $\mathrm{MHz}$. However, there is no intention to realize electronic adjusting of the natural (cutoff) frequency and quality factor $\left(f_{C}, Q\right)$.

Second example is quite interesting quadrature oscillator obtained by simple modification of the same SFG. Recently, many oscillator conceptions based on the current conveyors have been published, for example [34-50]. Some of these applications are not tunable [38, 41 and 42]. Some structures can be tuned by a single grounded resistor [34$37,39,46,47,49]$ or by a floating resistor $[40,43,50]$. The grounded variable resistor can be simply implemented by JFET, OTA or digital potentiometer. However using of the floating element is quite complicated. In several works [44-46] biasing current $\left(I_{b}\right)$, which drives the resistance $R_{x}$ of the terminal $X$ of the CC, is used for electronic control. However the parameter $\left(I_{b}, R_{x}\right)$ depends on the manufacturing deviations, supply voltage, temperature, etc. Therefore it can cause some problems with accuracy in the applications. The manufacturing tolerances of the $R_{x}$ can be tens of percent. There have been published oscillator circuits with the conveyors CCII which are based on single active block and four or five passive elements $[40,43,50]$. Furthermore circuits with two active blocks and four or six passive elements [36, 38-39,41, 44-46, 48] and at the most with three CCII and eight passive elements $[34,35,38,42,47,49]$ have been published. The circuits mentioned above were mostly verified through simulations at low frequencies only $(\mathrm{kHz})$ where the use of these high-speed blocks is not substantiated. In low frequency applications the classical approach based on the standard operational amplifiers and digital potentiometers for tuning can be sufficient. Another weakness of the previous approaches can be no availability of direct electronic controlling (except controlling $R_{x}$ for CCII), complicated implementation (too many blocks and elements), low level of the output signal $[43,44]$ and in some cases quite high THD [45].

\section{DISTRIBUTED SIGNAL FLOW GRAPH STRUCTURE OF AUTONOMOUS CIRCUIT AND DERIVED APPLICATIONS}

In Fig. 1 there is basic block signal flow graph of circuit structure. There are two current integrators where the first one is loss-less $\left(H_{1}(s)\right)$ and the second one is lossy $\left(H_{2}(s)\right)$ and two feedback branches $F_{1}$ and $F_{2}$ (in ideal case frequency independent). Different configuration of the feedback transfers allows to work in two types of applications. The first one is common multi-loop feedback filter and the second one is oscillator. The basic building blocks are current integrators employing classical three-port current conveyors of the second generation. 


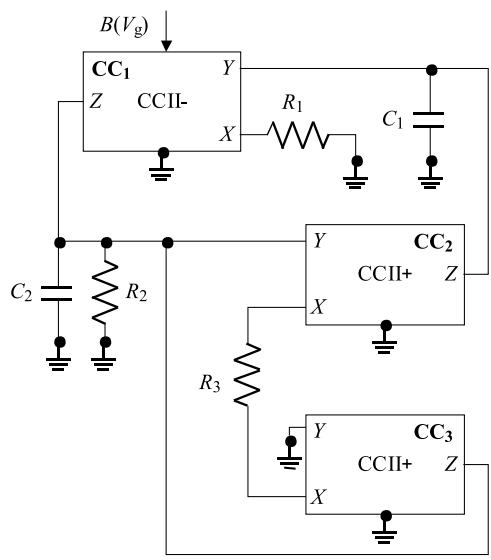

Fig. 5. Autonomous circuit with two loops of distributed feedback

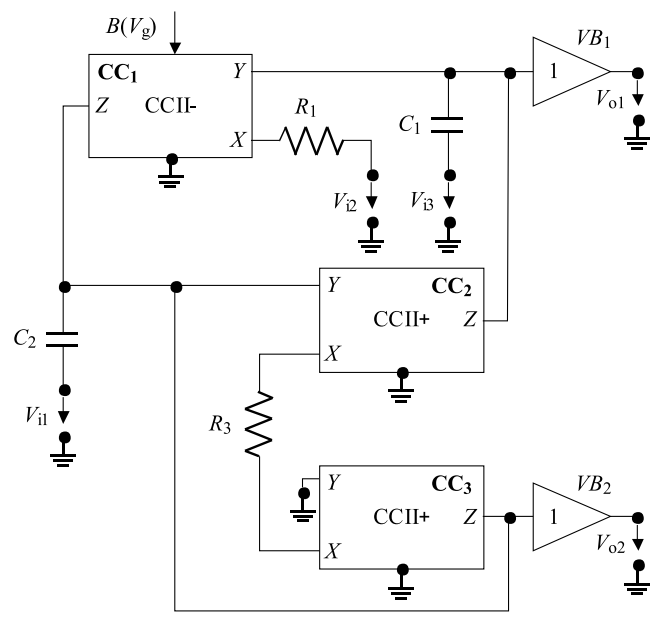

Fig. 6. Multifunctional filter configuration

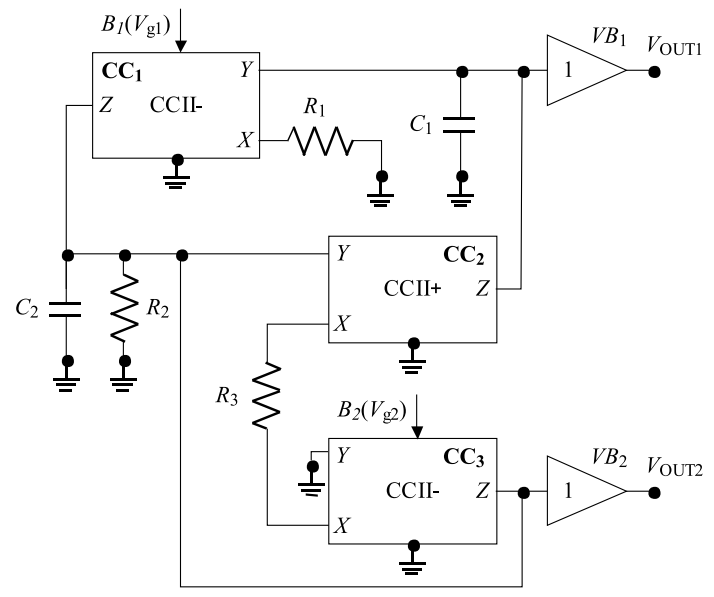

Fig. 7. Full adjustable quadrature oscillator

The Loss-less type of integrator with adjustable CCII- is presented in Fig. 2. The current gain $(B)$ of the CCII(negative) can be adjusted by external DC current [51]. It will be commented later in more details. In Fig. 3 and Fig. 4 there are two types of lossy current-mode integrators which are based on two CCII+ or CCII+ and CCII-. The first one with opposite polarities of the output signal and the second one with identical polarities of the output signal. In the modified version of the lossy integrator the current transfer of one output is controlled by adjustable current gain $B$.

The autonomous circuit employing three simple current conveyors (positive and negative types, some of them have electronically adjustable current gains) and five passive elements is presented in Fig. 5. According to the specific application there are four or five passive elements. Almost all of them are grounded. In the first case the autonomous circuit can work as biquad filter. In this application there is not necessary lossy integrator, therefore we can save resistor $R_{2}$ (Fig. 6). The oscillator configuration can be obtained if the feedback transfer $F_{2}$ is inverted. Therefore different configuration of $\mathrm{CC}_{3}$ is necessary. The modification described in Fig. 7 is very useable because the controllable negative type of CCII enables to use the electronic control of the condition of oscillation (CO). Now the feedback transfer is $F_{2}=-B_{2}$. Common commercially available CCII+ (ie AD 844 [52]), not allows the current gain control. One disadvantage is floating resistor between current inputs of $\mathrm{CC}_{2}$ and $\mathrm{CC}_{3}$. Voltage buffers in Fig. 6 and 7 are used for impedance separation of high impedance nodes. Transfers of branches in SFG (Fig. 1) are summarized in Tab. 1.

Table 1. Derived configuration and applications of structure in Fig. 1

\begin{tabular}{lccccc}
\hline no. & application & $H_{1}(s)$ & $H_{2}(s)$ & $F_{1}$ & $F_{2}$ \\
\hline 1 & autonomous circuit & & $\frac{-R_{2}}{R_{3}\left(s R_{2} C_{2}+1\right)}+1$ & +1 \\
2 & filter (loss-less integrators) & $\frac{B}{s R_{1} C_{1}}$ & $\frac{-1}{s R_{3} C_{2}}$ & +1 & +1 \\
3 & quadrature oscillator & (with electronic control) & $\frac{B_{1}}{s R_{1} C_{1}}$ & $\frac{-R_{2}}{R_{3}\left(s R_{2} C_{2}+1\right)}+1$ & $-B_{2}$ \\
& & & & \\
\hline
\end{tabular}

Characteristic equation of the circuit in Fig. 5 has following form given by Mason formula [53]

$$
\begin{gathered}
\Delta=1-\left(L_{1}+L_{2}\right)=1-\left(F_{1} H_{1}(s) H_{2}(s)+F_{2} H_{2}(s)\right)=0, \\
\Delta_{1}=s^{2}+\frac{R_{3}+R_{2}}{R_{2} R_{3} C_{2}} s+\frac{B}{R_{1} R_{3} C_{1} C_{2}}=0 .
\end{gathered}
$$

Frequency of natural pole and quality factor are given by

$$
\begin{gathered}
\omega_{C}=\sqrt{\frac{B}{R_{1} R_{3} C_{1} C_{2}}}, \\
Q=\frac{R_{2} R_{3} C_{2}}{R_{3}+R_{2}} \sqrt{\frac{B}{R_{1} R_{3} C_{1} C_{2}}} .
\end{gathered}
$$

Sensitivity of the frequency of the pole and quality factor to values of passive elements and parameters are

$$
\begin{gathered}
S_{R_{1}}^{\omega_{C}}=S_{R_{3}}^{\omega_{C}}=S_{C_{1}}^{\omega_{C}}=S_{C_{2}}^{\omega_{C}}=-S_{B}^{\omega_{C}}=-\frac{1}{2}, S_{R_{2}}^{\omega_{C}}=0, \\
S_{R_{1}}^{Q}=S_{C_{1}}^{Q}=-S_{C_{2}}^{Q}=-\frac{1}{2},
\end{gathered}
$$




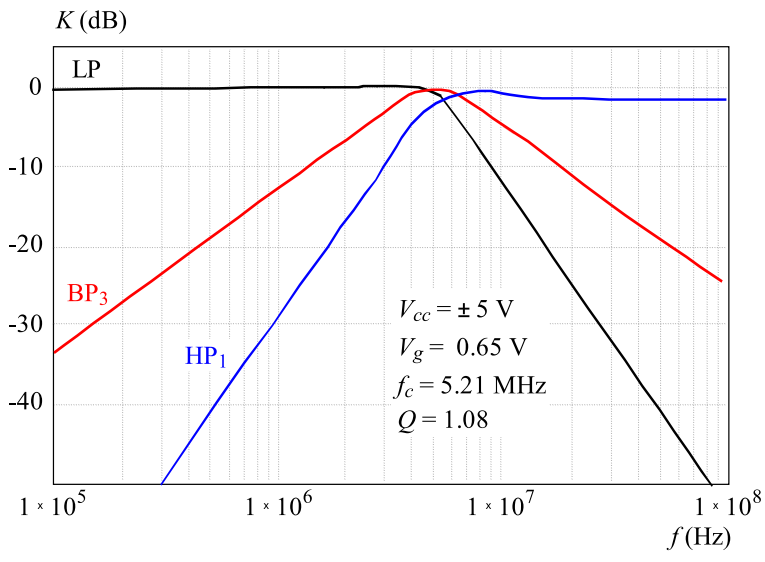

Fig. 8. Simulated magnitude responses of the filter in Fig. 6

$$
S_{R_{2}}^{Q}=\frac{R_{3}}{R_{2}+R_{3}}, S_{R_{3}}^{Q}=\frac{R_{3}}{R_{2}+R_{3}}-\frac{1}{2}, S_{B}^{Q}=\frac{1}{2} .
$$

Characteristic equation and quality factor of the filter in Fig. 6 are

$$
\begin{gathered}
\Delta_{2}=s^{2}+\frac{1}{R_{3} C_{2}} s+\frac{B}{R_{1} R_{3} C_{1} C_{2}}=0, \\
\omega_{C}=\sqrt{\frac{B}{R_{1} R_{3} C_{1} C_{2}}}, \quad Q=R_{3} C_{2} \sqrt{\frac{B}{R_{1} R_{3} C_{1} C_{2}}} .
\end{gathered}
$$

The value of natural frequency is the same as in (1). Therefore sensitivities are very similar as in previous case. Differences are in some dependence of sensitivities of quality factor on

$$
S_{R_{2}}^{Q}=0, \quad S_{R_{3}}^{Q}=\frac{1}{2} .
$$

Available transfer functions have following forms

$$
\begin{aligned}
K_{H P 1}(s) & =\frac{V_{o 2}}{V_{i 1}}=\frac{s^{2}}{\Delta_{2}}, \\
K_{H P 2}(s) & =\frac{V_{o 1}}{V_{i 3}}=\frac{s^{2}+\left(1 / R_{3} C_{2}\right) s}{\Delta_{2}}, \\
K_{B P 1}(s) & =\frac{V_{o 2}}{V_{i 2}}=\frac{\left(B / R_{1} C_{2}\right) s}{\Delta_{2}}, \\
K_{B P 2}(s) & =\frac{V_{o 2}}{V_{i 3}}=\frac{-\left(B / R_{1} C_{2}\right) s}{\Delta_{2}}, \\
K_{B P 3}(s) & =\frac{V_{o 1}}{V_{i 1}}=\frac{\left(1 / R_{3} C_{1}\right) s}{\Delta_{2}}, \\
K_{L P} & =\frac{V_{o 1}}{V_{i 2}}=\frac{B /\left(R_{1} R_{3} C_{1} C_{2}\right)}{\Delta_{2}} .
\end{aligned}
$$

Unused inputs are grounded. Strong disadvantage of the mentioned filter is dependence of quality factor on $B$ together with $f_{C}$ (independent changes of $f_{C}$ and $Q$ by current transfer of CCII-s are difficult). However there is a possibility of fully adjustable implementation of CCII-s with controllable current gains $[54,55]$.

Second available application of SFG in Fig. 1 is quadrature oscillator. Characteristic equation, oscillation

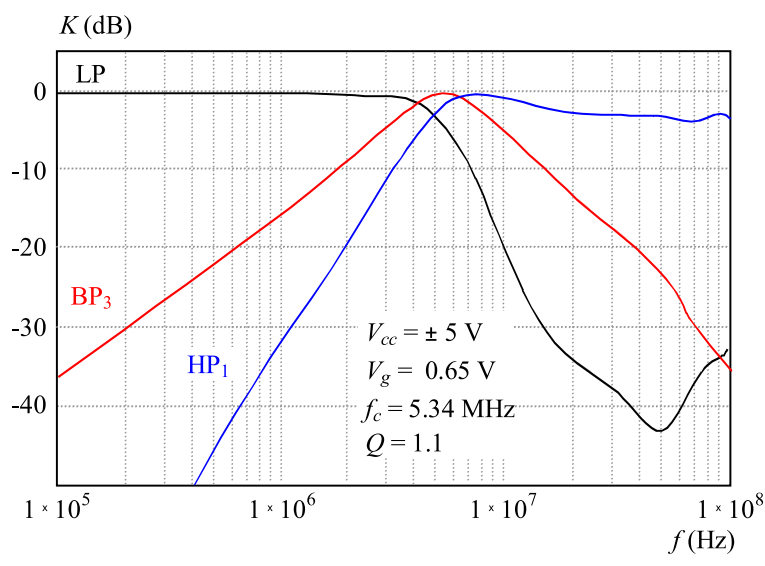

Fig. 9. Measured magnitude responses of the filter in Fig. 6

condition and oscillation frequency of the oscillator in Fig. 7 are

$$
\begin{gathered}
\Delta_{3}=s^{2}+\frac{R_{3}-R_{2} B_{2}}{R_{3} R_{2} C_{2}} s+\frac{B_{1}}{R_{1} R_{3} C_{1} C_{2}}=0, \\
R_{3}=R_{2} B_{2}, \quad \omega_{0}=\sqrt{\frac{B_{1}}{R_{1} R_{3} C_{1} C_{2}}} .
\end{gathered}
$$

Dependence of sensitivities of oscillation frequency on circuit parameters (passive and active) are

$$
S_{R_{1}}^{\omega_{0}}=S_{R_{3}}^{\omega_{0}}=S_{C_{1}}^{\omega_{0}}=S_{C_{2}}^{\omega_{0}}=-S_{B_{1}}^{\omega_{0}}=-\frac{1}{2}, S_{R_{2}}^{\omega_{0}}=S_{B_{2}}^{\omega_{0}}=0 .
$$

Thanks to the $\mathrm{CO}$ which can be adjustable by the current transfer $\left(B_{2}\right)$ the implementation of the circuit for amplitude stabilization can be quite simple.

\section{SIMULATION AND EXPERIMENTAL RESULTS}

For the verification there were used two types of the available current conveyors. The positive type is diamond transistor OPA 860 [56] (known also as transconductance amplifier) and negative one is the so called controllable current mode multiplier EL 2082 [57]. Both are recommended for fast and high frequency applications. The current gain of OPA 860 (works as CCII+) is constant but the current gain (marked as B) of the EL 2082 (CCII) is variable in the range from 0 to 4 (for DC control voltage $V_{g}$ from 0 to $5 \mathrm{~V}$ ). The disadvantage is nonlinear dependence of $B=f\left(V_{g}\right)$ [51].

Circuits in Figs. 6 and 7 were tested in PSpice and by measurement using network analyzer Agilent E5071C (ENA series) and oscilloscope Tektronix 2024. The filter was verified for $f_{C}=5.2 \mathrm{MHz}$. The following values of circuit parameters were designed: $R_{1}=455 \Omega$, $R_{2}=470 \Omega, C_{1}=C_{2}=47 \mathrm{pF}, V_{g}=0,65 \mathrm{~V}$. Selected magnitude responses are presented in Fig. 8. Important second order transfer function $\left(\mathrm{HP}_{1}, \mathrm{BP}_{3}\right.$ and $\left.\mathrm{LP}\right)$ are depicted. Circuit was also measured and important results are given in Fig. 9. An observable shift of obtained 


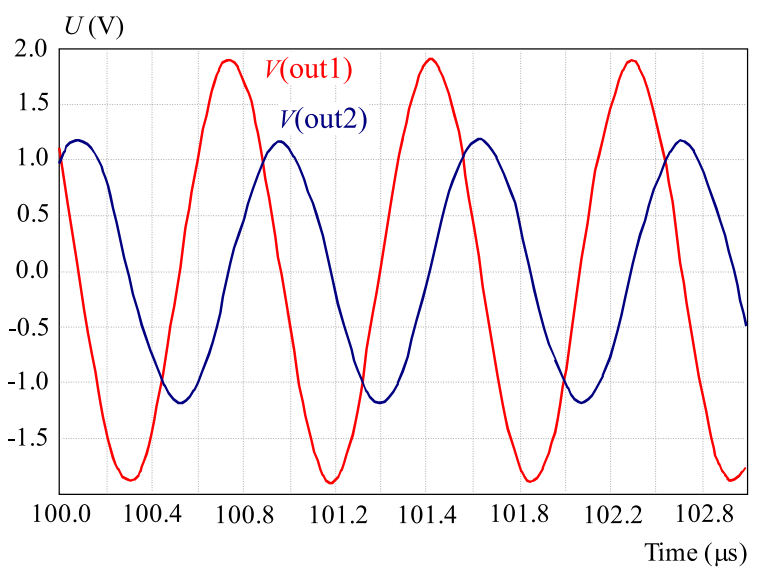

Fig. 10. Simulated transient response of quadrature oscillator

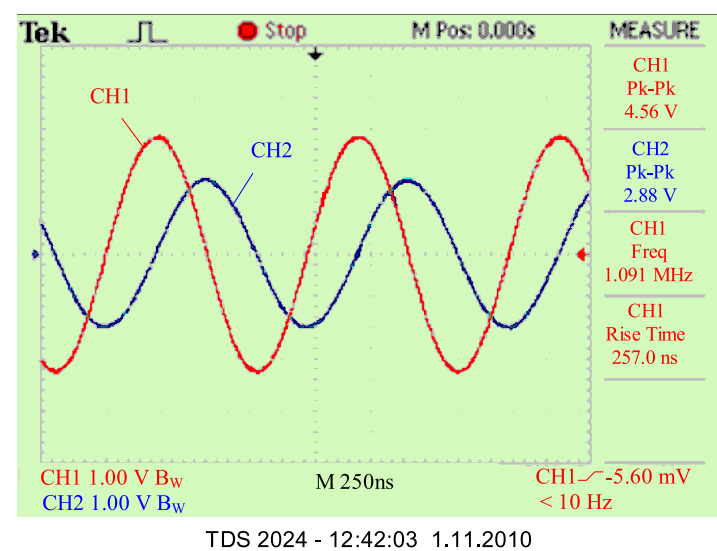

Fig. 12. Measured output transient responses

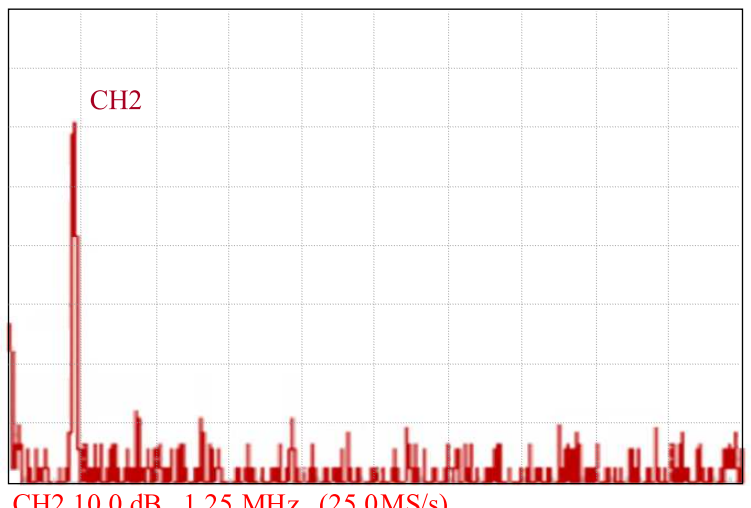

Fig. 14. Measured FFT spectrum (output 2)

$f_{C}$ is obvious. Connection, small-signal properties of used active elements, parasitic feedbacks and capacities in testing PCB, etc have influence on the LP stop-band response.

Second very useful application is quadrature oscillator (a variant in Fig. 7). The oscillator was designed for $f_{0}=$ $1 \mathrm{MHz}$. Calculated parameters of the passive elements and the current gains are $R_{1}=R_{3}=910 \Omega, R_{2}=1 \mathrm{k} \Omega$, $C_{1}=C_{2}=C=220 \mathrm{pF}, B_{1}=2.3\left(V_{g 1}=2.5 \mathrm{~V}\right)$ and $B_{2}=1\left(V_{g 2}=0.989 \mathrm{~V}\right)$. Results of simulation for time

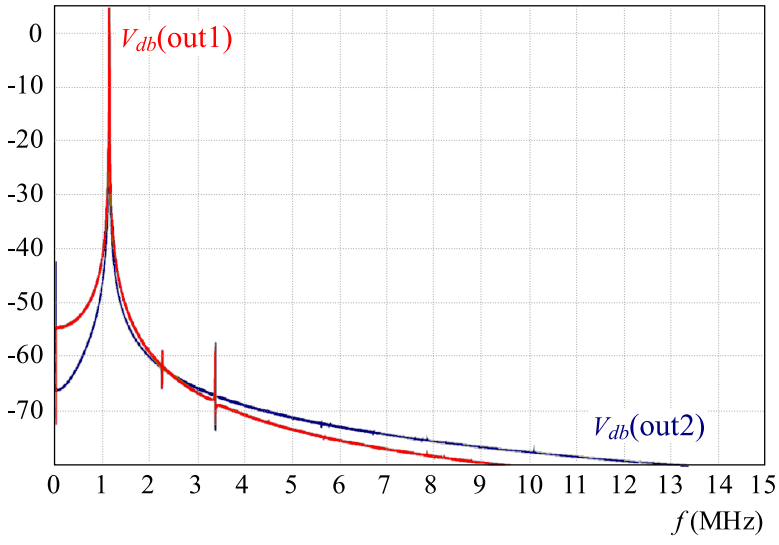

Fig. 11. Simulated spectrum of output amplitudes of the quadrature oscillator

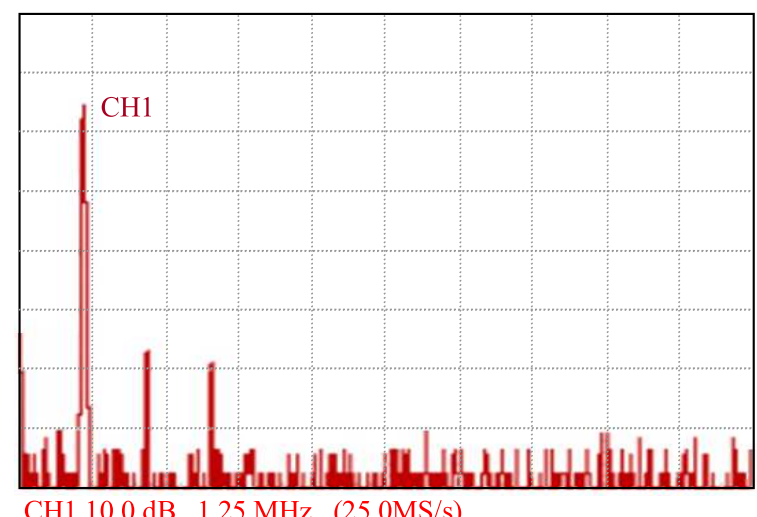

Fig. 13. Measured FFT spectrum (output 1)

domain and spectral domain are in Fig. 10 and Fig. 11. Output voltage with higher signal level is available on output 1 .

Table 2. Experimental results for different values of oscillation frequencies

\begin{tabular}{cccccccc}
\hline$V_{g 1}$ & $B_{1}$ & $V_{g 2}$ & $B_{2}$ & \multicolumn{2}{c}{$f_{0}(\mathrm{MHz})$} & $\mathrm{THD}_{1}$ & $\mathrm{THD}_{2}$ \\
$(\mathrm{~V})$ & $(-)$ & $(\mathrm{V})$ & $(-)$ & ideal & measured & $(\%)$ & $(\%)$ \\
\hline 3.00 & 2.70 & 0.985 & 0.99 & 1.180 & 1.250 & 1.30 & 0.32 \\
2.50 & 2.30 & 0.989 & 0.99 & 1.090 & 1.150 & 0.71 & 0.32 \\
2.00 & 1.90 & 0.995 & 1.00 & 0.987 & 1.030 & 0.79 & 0.32 \\
1.50 & 1.40 & 1.001 & 1.00 & 0.848 & 0.899 & 0.64 & 0.35 \\
1.00 & 1.00 & 1.006 & 1.01 & 0.716 & 0.732 & 0.64 & 0.32 \\
0.50 & 0.52 & 1.014 & 1.01 & 0.517 & 0.536 & 1.05 & 0.18 \\
0.20 & 0.20 & 1.018 & 1.02 & 0.320 & 0.353 & 1.46 & 0.59 \\
0.10 & 0.10 & 1.023 & 1.02 & 0.227 & 0.260 & 1.15 & 0.89 \\
\hline
\end{tabular}

Some examples of the measured output responses in time domain and frequency domain for fixed parameters $V_{g 1}=2.2 \mathrm{~V}, V_{g 2}=0.99 \mathrm{~V},\left(f_{0}=1.09 \mathrm{MHz}\right)$ are in Figs. 12-14. Higher value of total harmonic distortion - THD (observable spectral $2^{\text {nd }}$ and $3^{\text {th }}$ harmonics components) on output 1 is caused by higher gain (voltage to current transformation constant given by value of $R_{3}$ re- 


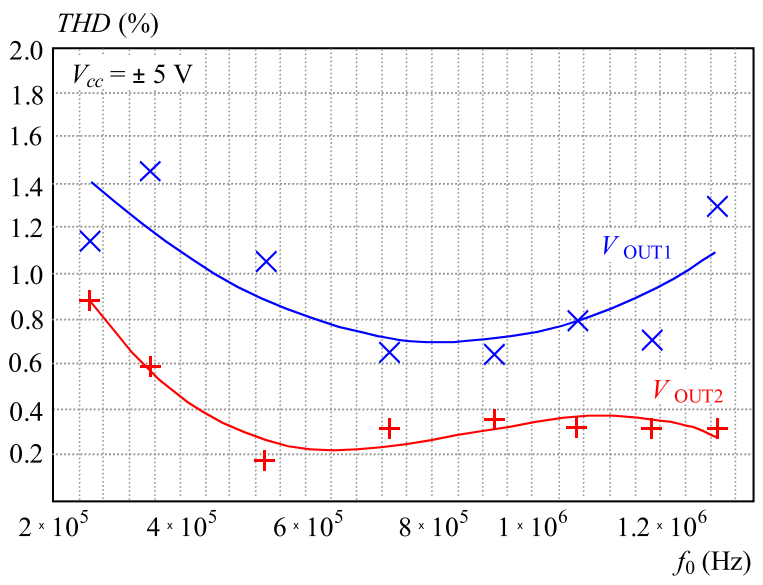

Fig. 15. Dependence of THD on oscillation frequency

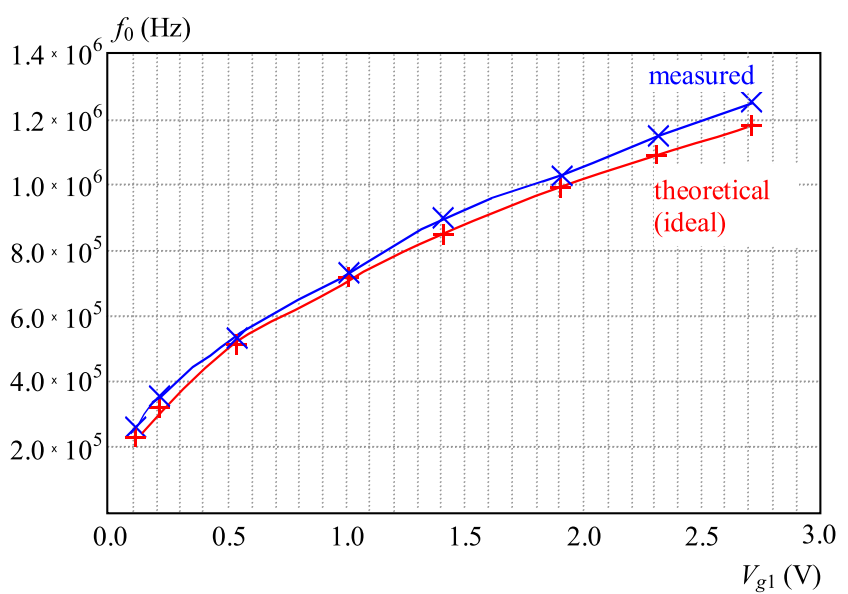

Fig. 16. Dependence of oscillation frequency $f_{0}$ on control voltage $V_{g 1}$

Table 3. Small signal parasitic properties

\begin{tabular}{cllccccc}
\hline index designation & $\begin{array}{l}\text { manufactured } \\
\text { product }\end{array}$ & $\begin{array}{c}C_{y} \\
(p F)\end{array}$ & $\begin{array}{c}C_{z} \\
(p F)\end{array}$ & $\begin{array}{c}R_{y} \\
(\mathrm{M} \Omega)\end{array}$ & $\begin{array}{c}R_{z} \\
(\mathrm{M} \Omega)\end{array}$ & $\begin{array}{c}R_{x} \\
(\Omega)\end{array}$ \\
\hline 1 & CC1 (CCII-) & EL 2082 [58] & 2 & 5 & 2 & 1 & 95 \\
2 & CC2 (CCII+) & OPA 860 [57] & 2 & 2 & 0.455 & 0.054 & 11 \\
3 & CC3 (CCII+) & OPA 860 [57] & 2 & 2 & 0.455 & 0.054 & 11 \\
\hline
\end{tabular}

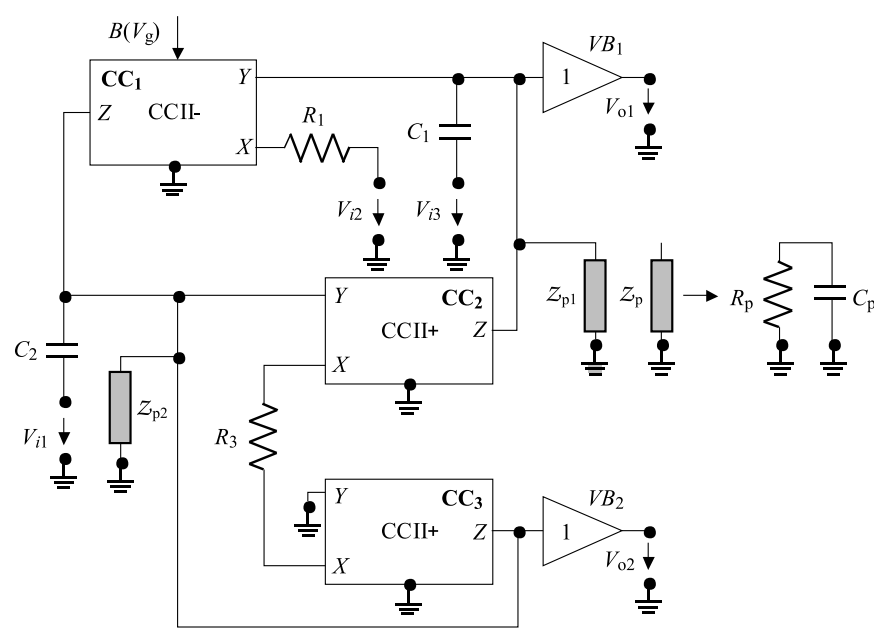

Fig. 17. Non-ideal features in designed filter

spectively) and more steeper and less linear input-output characteristic of $\mathrm{CC}_{2}$ (OPA 860).

Further analysis also reveals that $V_{\text {out } 2}$ is dependent on parameter $B_{1}\left(V_{g 1}\right)$ according to the following equation (we suppose $R_{1}=R_{2}=R_{3}=R$ and $C_{1}=C_{2}=C$ )

$$
V_{\text {out } 2}=\frac{-j}{\sqrt{B}_{1}} V_{\text {out } 1}=\frac{1}{s q r t B_{1}} V_{\text {out } 1} e^{-\frac{\pi}{2} j}
$$

It means that for very low $B_{1}$ (the lowest frequencies) amplitude of $V_{\text {out } 2}$ achieves large level and THD therefore increases because produced amplitude reaches nonlinear areas of dynamic transfer characteristics or saturation level of active elements.
Experimental measurements have provided interesting results which are summarized in Tab. 2. Presented results were obtained without using of the circuit for amplitude stabilization. It is obvious that the oscillation condition has to be set very carefully $\left(V_{g 2}\right)$ in each measurement point to keep THD at low values. Some features of the circuit are also presented graphically (Figs. 15 and 16).

\section{DISCUSSION OF PARASITIC INFLUENCES}

From Fig. 8 and Fig. 9 it is clear that HP1 response is influenced by parasitic features on higher frequencies (above $10 \mathrm{MHz}$ ) in the pass-band. Further analysis reveals the reason of this drawback. The filter from Fig. 6 which includes parasitic input and output impedances of CC1CC3 is depicted in Fig. 17. There are two the most important nodes which contains $Z_{p 1}$ and $Z_{p 2}$.Please rewrite: Influence of the input resistance of used voltage buffer (internal buffer in OPA 860) can be neglected (in comparison with other impedances in important nodes is quite high). These small signal parameters of the used active elements are in Tab. 3. Typical parameters are called accordingly to the conveyor port notation.

We can evaluate important values which have effect on behavior of HP1 pass-band. From Tab. 3 we can determined that $C_{p 1}=C_{y 1}+C_{z 2}=2+2=4 \mathrm{pF}, R_{p 1}=$ $R_{y 1} R_{z 2} /\left(R_{y 1}+R_{z 2}\right)=52.6 \mathrm{k} \Omega, C_{p 2}=C_{z 1}+C_{y 2}+C_{z 3}=$ $5+2+2=9 \mathrm{pF}, R_{p 2}=1 /\left(1 / R_{z 1}+1 / R_{y 2}+1 / R_{z 3}\right)=$ $46 \mathrm{k} \Omega, R_{3}^{*}=R_{3}+R_{x 2}+R_{x 3}=470+2 \times 11=492 \Omega$, $R_{1}^{*}=R_{1}+R_{x 1}=360+95=455 \Omega$. Now the determinant 
of the transfer function (characteristic equation) has form

$\Delta_{2}^{*}=s^{2}+$

$$
\begin{gathered}
\frac{1}{R_{1}^{*} R_{3}^{*} R_{p 1} R_{p 2}\left(C_{1} C_{p 2}+C_{2} C_{p 1}+C_{p 1} C_{p 2}+C_{1} C_{2}\right)} \times \\
\left\{R_{1}^{*} R_{3}^{*}\left[R_{p 1}\left(C_{1}+C_{2}\right)+R_{p 2}\left(C_{2}+C_{p 2}\right)\right]+\right. \\
\left.R_{1}^{*} R_{p 1} R_{p 2}\left(C_{1}+C_{p 1}\right)\right\} s \\
+\frac{R_{1}^{*} R_{3}^{*}+R_{p 2}\left(R_{p 1} B+R_{1}^{*}\right)}{R_{1}^{*} R_{3}^{*} R_{p 1} R_{p 2}\left(C_{1} C_{p 2}+C_{2} C_{p 1}+C_{p 1} C_{p 2}+C_{1} C_{2}\right)} .
\end{gathered}
$$

Transfer function of HP1 has form

$$
K_{H P 1}^{*}=\frac{s^{2}+\left(1 /\left(R_{p 1}\left(C_{1}+C_{p 1}\right)\right) s\right.}{\Delta_{2}^{*}} .
$$

The transfer at higher frequencies is given by

$$
K_{H P 1 \_H F}(\omega \rightarrow \infty)=\frac{C_{2}}{C_{2}+C_{p 2}} .
$$

The exact value of magnitude above $10 \mathrm{MHz}$ is

$$
\begin{aligned}
\mid K_{H P_{-} H F}(\omega & \rightarrow \infty) \mid=\frac{C_{2}}{C_{2}+C_{p 2}}= \\
& \frac{47 \times 10^{-12}}{47 \times 10^{-12}+9 \times 10-12}=0.84 \rightarrow-1.5 \mathrm{~dB},
\end{aligned}
$$

which is corresponding to the simulation and measurement results. Analysis shows that problem in HP passband is caused mainly by $C_{p 2}$ (parasitic capacitances in this node). Similarly there is a problem with finite attenuation in the stop band (at low frequencies) of the $\mathrm{BP}_{1}$ where the transfer is in the form

$$
K_{B P 1}^{*}(s)=\frac{1}{\Delta_{2}^{*}} \frac{B\left(s\left(R_{p 1} C_{1}+R_{p 1} C_{p 1}\right)+1\right)}{R_{1}^{*} R_{p 1}\left(C_{1}+C_{p 1}\right)\left(C_{2}+C_{p 2}\right)},
$$

from where

$$
\left|K_{B P 1 \_L F}(\omega \rightarrow 0)\right|=\frac{B R_{3} R_{p 2}}{R_{1}^{*}\left(R_{3}^{*}+R_{p 2}\right)+B R_{p 1} R_{p 2}} .
$$

For numerical values of the parameters the value of the attenuation at low frequencies is $\left|K_{B P 1 \_L F}\right|=-40.6 \mathrm{~dB}$ and the frequency of the zero is $f_{Z}=\frac{1}{2 \pi R_{p 1}\left(C_{1}+C_{p 1}\right)}=$ $59 \mathrm{kHz}$. Other transfer characteristics of the filter are influenced much lower than the characteristics mentioned above.

In the case of the oscillator circuit (Fig. 7) we can introduce the model in Fig. 18. Influences of real active elements on some circuit parameters are focused to the same nodes as in the previous case. In this case we can determine that $R_{1}^{*}=R_{1}+R_{x 1}=910+95=1005 \Omega$, $R_{3}^{*}=R_{3}+R_{x 2}+R_{x 3}=910+11+95=1016 \Omega, R_{p 1}=$ $1 /\left(1 / R_{z 2}+1 / R_{y 1}\right) 52.6 \mathrm{k} \Omega$ and $R_{p 2}=1 /\left(1 / R_{z 1}+1 / R_{y 2}+\right.$ $\left.1 / R_{z 3}\right) 240 \mathrm{k} \Omega$. Parasitic capacitances have approximate values $C_{p 1}=C_{z 2}+C_{y 1}=4 \mathrm{pF}$ and $C_{p 2}=C_{z 1}+C_{y 2}+$ $C_{z 3}=12 \mathrm{pF}$.
Characteristic equation has the form

$$
\begin{gathered}
\Delta_{3}^{*}=a_{2}^{*} s^{2}+a_{1}^{*} s+a_{0}^{*}, \\
a_{2}^{*}=1 \\
a_{1}^{*}=\frac{1}{R_{1}^{*} R_{2} R_{3}^{*} R_{p 1} R_{p 2}\left(C_{1} C_{2}+C_{1} C_{p 1}+C_{2} C_{p 2}+C_{p 1} C_{p 2}\right)} \\
\times\left\{R_{1}^{*} R_{2} R_{3}^{*}\left(R_{p 1} C_{2}+R_{p 2} C_{1}+R_{p 1} C_{p 1}+R_{p 2} C_{p 2}\right)+\right. \\
R_{1}^{*} R_{p 1} R_{p 2}\left(C_{p 1} R_{3}^{*}+C_{2} R_{3}^{*}-B_{2} R_{2}\left(C_{p 1}+C_{p 2}\right)\right\}, \\
a_{0}^{*}=\frac{R_{1}^{*} R_{3}^{*}\left(R_{2}+R_{p 2}\right)+R_{2} R_{p 2}\left(B_{1} R_{p 1}-B_{2} R_{1}^{*}\right)}{R_{1}^{*} R_{2} R_{3}^{*} R_{p 1} R_{p 2}\left(C_{1} C_{2}+C_{1} C_{p 1}+C_{2} C_{p 2}+C_{p 1} C_{p 2}\right)} .
\end{gathered}
$$

Oscillation condition and oscillation frequency are

$$
\begin{aligned}
& R_{1}^{*} R_{2} R_{3}^{*}\left(R_{p 1} C_{2}+R_{p 2} C_{1}+R_{p 1} C_{p 1} R_{p 2} C_{p 2}\right)+ \\
& R_{1}^{*} R_{p 1} R_{p 2}\left(C_{p 1} R_{3}^{*}+C_{2} R_{3}\right)=R_{1}^{*} R_{p 1} R_{p 2} B_{2} R_{2}\left(C_{p 1}+C_{2}\right),
\end{aligned}
$$

$\omega_{0}^{*}=$

$$
\sqrt{\frac{R_{1}^{*} R_{3}^{*}\left(R_{2}+R_{p 2}\right)+R_{2} R_{p 2}\left(B_{1} R_{p 1}-B_{2} R_{1}^{*}\right)}{R_{1}^{*} R_{2} R_{3}^{*} R_{p 1} R_{p 2}\left(C_{1} C_{2}+C_{1} C_{p 1}+C_{2} C_{p 2}+C_{p 1} C_{p 2}\right)}} .
$$

Now it is clear that oscillation frequency and $\mathrm{CO}$ are not independent on each other. However, influence of $B_{2}$ is minimal, because product of $B_{1} R_{p 1} \gg B_{2} R_{1}$ (from the previous analysis $R_{p 1}=52.6 \mathrm{k} \Omega$ but $R_{1}$ is only few hundreds $\Omega$ ). The resistors $R_{x}$ (resistances in the current inputs of used CC have large fabrication tolerance and inaccuracy) influence remarkably the circuit properties. They decrease the accuracy of $f_{0}$ and have impact on the start of the oscillations. From Tab. 3 the shift of the measured oscillation frequency is obvious $(50-80 \mathrm{kHz})$.

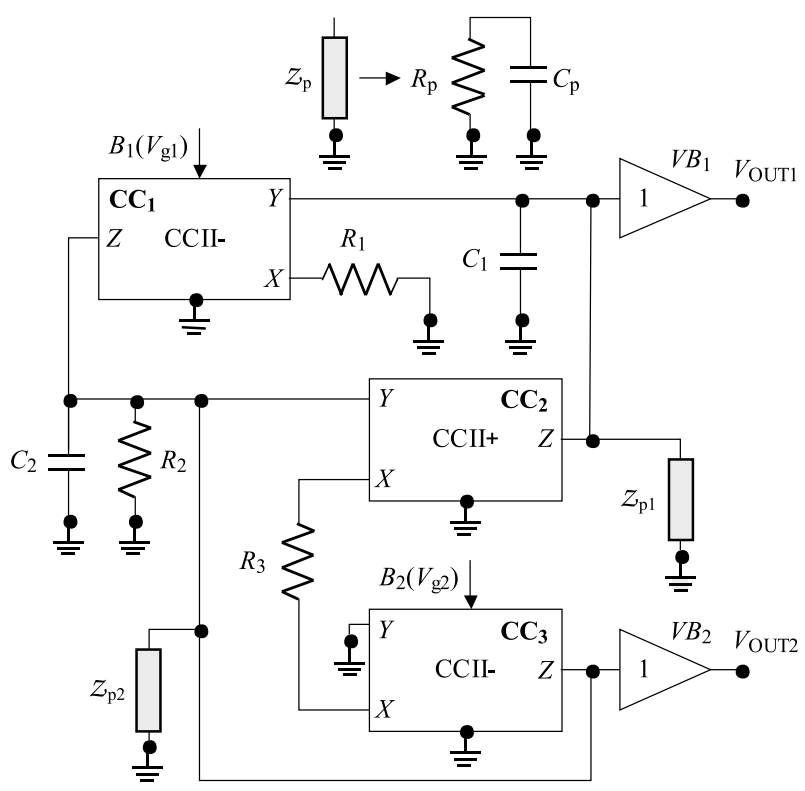

Fig. 18. Oscillator with non-ideal properties 


\section{CONCLUSION}

In the paper interesting and quite simple approach of the design of the multi loop structure leading to the filters or oscillators circuits is presented. The solution based on the distributed signal flow graph synthesis and other modifications of the integrator feedback structure is presented. The positive and negative adjustable three-port current conveyors are used in this design. Solution can provide multifunctional filter and quadrature oscillator with full electronic independent adjusting of oscillation frequency and oscillation condition. Full adjusting means that oscillation frequency $\left(f_{0}\right)$ and condition of oscillation $(\mathrm{CO})$ can be independently electronically driven by external DC control voltage. In the previous publications there were reported many quadrature oscillators however adjusting of the mentioned important parameters is possible only through passive elements or $R_{x}$ value. Some solutions, for example in [42,47 and 49] which have been published in the past are similar (similar number of active and passive elements), however they are based on different synthesis approaches and without direct (by control voltage or current driving parameter of active element) electronic adjusting of $f_{0}$ and CO. The complexity of the proposed oscillator circuit is proportionate to the achievable possibilities of adjusting. There are only few passive elements and many of them are grounded (mainly capacitors). Due to the great frequency features of the used active elements it is possible to obtain applications working at quite high frequencies (several $\mathrm{MHz}$, video band). This is documented by simulation and measurement results. Presented multifunctional filter operates in the range of several units and tens $\mathrm{MHz}$ and the quadrature oscillator is tunable from 0.2 to $1.3 \mathrm{MHz}$ (for $C=220 \mathrm{pF}$ ). Achievable THD is from 0.2 to $1.5 \%$ in the whole range without using of the circuit for amplitude stabilization.

\section{Acknowledgement}

The research described in the paper was supported by the Czech Ministry of Education under research program MSM 0021630513 and Czech Science Foundation projects under No. 102/08/H027, No. 102/09/P217 and No. $102 / 09 / 1681$. Research described in the paper is a part of the COST Action IC0803 RF/Microwave communication subsystems for emerging wireless technologies, financed by the Czech Ministry of Education by the grant No. OC09016. The support of the project CZ.1.07/2.3.00/20.0007 WICOMT, financed from the operational program Education for competitiveness, is gratefully acknowledged.

\section{REFERENCES}

[1] BIOLEK, D.-SENANI, R.-BIOLKOVA, V.-KOLKA, Z. : Active Elements for Analog Signal Processing: Classification, Review, and New Proposal, Radioengineering 17 No. 4 (2008), 15-32.
[2] BIOLEK, D.-BIOLKOVA, V.-KOLKA, Z.: Universal Current-Mode OTA-C KHN Biquad, International Journal of Electronics, Circuits and Systems 1 No. 4 (2007), 214-217.

[3] CHUnguA, W.-LING, Z.-TAO, L.: A New OTA-C Current-Mode Biquad Filter with Single Input and Multiple Outputs, International Journal of Electronics and Communications AEU 62 (2008), 232-234.

[4] SOTNER, R.-PETRZELA, J.-SLEZAK, J. : Current-Controlled Current-Mode Universal Biquad Employing Multi-Output Transconductors, , Radioengin. 18 No. 3 (2009), 285-294.

[5] WANG, C.-ZHAO, Y.-ZHANG, Q.-DU, S. : A New Current Mode SIMO-Type Universal Biquad Employing Multi-Output Current Conveyors (MOCCIIs), Radioengineering 18 No. 1 (2008), 83-88.

[6] SOTNER, R.-SLEZAK, J.-DOSTAL, T.-PETRZELA, J : Universal Tunable Current-Mode Biquad Employing Distributed Feedback Structure with MO-CCCII, Journal of Electrical Engineering 61 No. 1 (2010), 52-56.

[7] MINAEI, S.-SAYIN, O. K.-KUNTMAN, H. : A New CMOS Electronically Tunable Current Conveyor and its Application to Current-Mode Filters, IEEE Transaction on Circuits and Systems I - Regular papers 53 No. 7 (2006), 1448-1457.

[8] KOTON, J.-HERENCSAR, N.-CICEKOGLU, O.-VRBA, K.: Current-Mode KHN Equivalent Frequency Filter using ECCIIs, Proceedings of the 33th International Conference on Telecommunications and Signal Processing - TSP 2010, Baden - Austria, 2010, pp. 27-30.

[9] MARCELLIS, A.-FERRI, G.-GUERRINI, N. C.-SCOTTI, G.-STORNELLI, V.-TRIFILETTI, A : The VGC-CCII: a Novel Building Block and its Application to Capacitance Multiplication, Analog Integrated Circuits and Signal Processing 58 No. 1 (2009), 55-59.

[10] KESKIN, A.-BIOLEK, D : Current Mode Quadrature Oscillator using Current Differencing Transconductance Amplifiers (CDTA), IEE Proceedings - Circuits, Devices and Systems 153 No. 3 (2006), 214-217.

[11] BIOLEK, D.-KESKIN, A.-BIOLKOVÁ, V. : Quadrature Oscillator using CDTA-Based Integrators, WSEAS Transactions on Electronics 3 No. 9 (2006), 463-469.

[12] PROKOP, R.-MUSIL, V.: Modular Approach to Design of Modern Circuit Blocks for Current Signal Processing and New Device CCTA, Proceedings of the Seventh IASTED International Conference on Signal and Image Processing, 2005, pp. 494-499.

[13] PROKOP, R.-MUSIL, V.: New Modular Current Devices for True Current Mode Signal Processing, Electronics 16 No. 4 (2007), 36-42.

[14] SIRIPRUCHYANUN, M.-JAIKLA, W. : Current Controlled Current Conveyor Transconductance Amplifier (CCCCTA): a Building Block for Analog Signal Processing, Electrical Engineering 90 No. 6 (2008), 443-453, Springer.

15] HERENCSAR, N.-VRBA, K.-KOTON, J.-LATTENBERG, I. : The Conception of Differential-Input Buffered and Transconductance Amplifier (DBTA) and its Application, IEICE Electronics Express 6 No. 6 (2009), 329-334.

16] HERENCSAR, N.-KOTON, J.-VRBA, K.: Realization of current-Mode KHN-Equivalent Biquad using Current Follower Transconductance Amplifiers (CFTAs), IEICE Trans. Fundamentals E93-A No. 10 (2010), 1816-1819.

[17] JERABEK, J.-VRBA, K. : SIMO Type Low-Input and HighOutput Impedance Current-Mode Universal Filter Employing Three Universal Current Conveyors, International Journal of Electronics and Communications (AEU) 64 No. 6 (2010), 588-593.

[18] JERABEK, J.-SOTNER, R.-VRBA, K. : Fully-Differential Current Amplifier and its Application to Universal and Adjustable filter, International Conference on Applied Electronics. Plzeň: University of West Bohemia, 2010, pp. 141-144. 
[19] JERABEK, J.-VRBA, K.: Multiple-Input Multiple-Output Universal Filter using Current Followers, Proceedings of the 31th International Conference on Telecommunications and Signal Processing - TSP' 2008. Budapest, Hungary: Asszisztencia Szervezo Kft., 2008, pp. 29-32.

[20] CHANG, C. M.: Current Mode Allpass/Notch and Bandpass Filter using Single CCII, Electronics Letters 27 No. 20 (1991, $1812-1813$.

[21] LIU, S.-KUO, J.-TSAY, J. : New CCII-Based Current-Mode Biquadratic Filters, International Journal of Electronics 72 No 2 (1992), 243-252.

[22] SHARMA, S.-RAJPUT, S. S.-PAL, K.-MANGOTRA, L. K.-JAMUR, S. S. : Low-Voltage CCII Based All-Pass/Notch Filter, Indian Journal of Pure and Applied Physics 44 No. 11 (2006), 871-874.

[23] KUMAR, M.-SRISTAVA, M. C.-KUMAR, U.: Tunable Multifunctional Filter using Current Conveyor, International Journal of Computer Science and Information Security 8 No. 1 (2010), 95-98.

[24] KUMAR, P.-PAL, K.: Variable Q All-Pass, Notch and Band-Pass Filters using Single CCII, Frequenz 59 No. 9-10 (2005), 235-239.

[25] SOLIMAN, A. M. : New All-Pass and Notch Filters using Current Conveyors, Frequenz 53 No. 3-4 (1999), 84-86.

[26] HIGASHIMURA, M.-FUKUI, Y.: Realization of All-Pass and Notch Filters using a Single Current Conveyor, International Journal of Electronics 65 No. 4 (1988, 823-828.

[27] MINAEI, S.-YUCE, E.-CICEKOGLU, O.: Electronically Tunable Multi-Input Single-Output Voltage-Mode Filter, Proceedings of the 2005 European Conference on Circuit Theory and Design, vol. 3, 2005, pp. III/401-III/404.

[28] TANGSRIRAT, W.: Current-Tunable Current-Mode Multifunctional Filter Based on Dual-Output Current-Controlled Conveyors, International Journal of Electronics and Communications (AEU) 61 No. 8 (2007), 528-533.

[29] SOLIMAN, A. M.: Current-Mode Universal Filters Using Current Conveyors: Classification and Review, Circuits Systems and Signal Processing 27 No. 3 (2008), 405-427.

[30] PANDEY, N.-PAUL, S. K.-JAIN, S. B. : Voltage Mode Universal Filter using Two Plus Type CCIIs, Int. J. of Active and Passive Electronic Devices 3 No. 2 (2008), 165-173.

[31] CHEN, H. P.: Single CCII-Based Voltage-Mode Universal Filter, Analog Integrated Circuits Signal Processing 62 No. 2 (2010), 259-262.

[32] LIU, S.-LEE, L.: Voltage-Mode Universal Filters using Two Current Conveyors, International Journal of Electronics 82 No. 2 (1997), 145-149.

[33] ABUelmaAtTi, M. T.-ShabRA, M. A.: A Novel Current-Conveyor-Based Universal Current-Mode Filter, Microelectronics Journal 27 No. 6 (1996), 471-475.

[34] HORNG, J. W.: Current Conveyors based Allpass Filters and Quadrature Oscillators Employing Grounded Capacitors and Resistors, Computers and Electrical Engineering 31 No. 1 (2005), 81-92.

[35] CHANG, C. M.: Novel Current-Conveyor-Based Single-Resistance-Controlled/Voltage-Controlled Oscillator Employing Grounded Resistors and Capacitors, Electronic Letters 30 No. 3 (1994), 181-183.

[36] KUMAR, V.-PAL, K. : Single Element Controlled Sinusoidal Oscillators using Current Conveyors, Journal of Active and Passive Electronic Devices 4 No. 3 (2009), 197-202.

[37] KUMAR, A.-VYAS, A. L.: A Single Resistance Controlled Eight Possible Oscillator Circuits for analog Signal Processing Applications, Academic Open Internet Journal 21 (2007), 1-7.

[38] TOKER, A.-KUNTMAN, H.-CICEKOGLU, O.-DISCIGIL, M. : New Oscillator Topologies using Inverting Second-Generation Current Conveyors, Turk. J. Elec. Engin. 10 No. 1 (2002), 119-129.
39] SHEN-IUAN, LIU : Single-Resistance-Controlled/Voltage Controlled Oscillator using Current Conveyors and Grounded Capacitors, Electronic Letters 31 No. 5 (1995), 337-338.

[40] AGGARWAL, V.: Novel Canonic Current Mode DDCC Based SRCO Synthesized using a Genetic Algorithm, Analog Integrated Circuits and Signal Processing 40 No. 1 (2004), 83-85.

[41] SOLIMAN, A. M. : Current-Mode Oscillators using Single Output Current Conveyors, Microelectronics Journal 29 No. 11 (1998), 907-912.

42] SOLIMAN, A. M.: Synthesis of Grounded Capacitor and Grounded Resistor Oscillators, Journal of the Franklin Institute 336 No. 4 (1999), 735-746.

43] LAHIRI, A.: Additional Realization of Single-Element-Controlled Oscillators using Single ICCII-, International Journal of Computer and Electrical Engineering 1 No. 3 (2009), 303-306.

44] PANDEY, N.-PAUL, K.: A Novel Electronically Tunable Sinusoidal Oscillator based on CCCII (-IR), Journal of Active and Passive Electronic Devices 3 No. 2 (2008), 135-141.

[45] HORNG, J. W.: A Sinusoidal Oscillator using Current-Controlled Current Conveyors, Int. Journal of Electronics 88 No. 6 (2001), 659-664.

[46] HORNG, J. W.-LIN, S.-YANG, CH. : Sinusoidal Oscillators using Current Conveyors and Grounded Capacitors, Journal of Active and Passive Electronic Devices 2 No. 2 (2007), 127-136.

[47] ABUELMAATTI, M. T. : New Sinusoidal Oscillators with Fully Uncoupled Control of Oscillation Frequency and Condition using Three CCII+s, Analog Integrated Circuits and Signal Processing 24 No. 3 (2000), 253-261.

[48] KHAN, A. A.-BIMAL, S.-DEY, K. K.-ROY, S. S. : Novel RC Sinusoidal Oscillator using Second-Generation Current Conveyor, IEEE Transaction on Instrumentation and Measurement 54 No. 6 (2005), 2402-2406.

49] MARTineZ, P. A.-SABADELL, J.-ALDEA, C-CELMA, S. : Variable Frequency Sinusoidal Oscillators based on CCII+, IEEE Transaction on Circuits and Systems-I: Fundamental Theory and Applications 46 No. 11 (1999), 1386-1390.

50] KILINC, S.-JAIN, V.-AGGARWAL, V.-CAM, U.: Catalogue of Variable Frequency and Single-Resistance-Controlled Oscillators Employing a Single Differential Difference Complementary Current Conveyor, Frequenz 60 No. 7-8 (2006), $142-146$.

51] SOTNER, R.-HRUBOS, Z.-SLEZAK, J.-DOSTAL, T. Simply Adjustable Sinusoidal Oscillator Based on Negative Three- Port Current Conveyors, Radioengineering 19 No. 3 (2010), 446-453.

[52] Analog Devices. Monolithic Op Amp AD 844, 2003, 16 p. Available at: http://www.analog.com.

[53] MASON, S. J.: Feedback Theory: Further properties of Signal Flow Graphs, Proc. IRE 44 No. 7 (1956), 920-926.

54] SOTNER, R.-SLEZAK, J.-DOSTAL, T.: ElectronicallyControlled Multifunctional Current Mode Filter based on Commercially Available Current Conveyors and Buffers, Proceedings of 19th International Conference Radioelektronika 2009, 2009, pp. 309-312.

55] SOTNER, R.-SLEZAK, J.-DOSTAL, T.: Multifunctional Electronically Tunable Current Mode Biquad using Commercially Available Current Conveyors, Proceedings of the 16th International Conference Mixed Design Of Integrated Circuits And Systems MIXDES 2009, 2009, pp. 652-655.

[56] Texas Instruments Inc. OPA 860 Wide Bandwidth Operational Transconductance Amplifier and Buffer, 2006, 32 p. Available at http://www.ti.com.

57] Intersil (Elantec). EL 2082CN Current-Mode Multiplier, 1996, 16 p. Available at: http://www.intersil.com.

Received 15 December 2010 